\title{
The contribution of fortified foods to micronutrient intake in Irish adults aged 18-64 years
}

\author{
A. Hennessy, E. Walsh, J. Walton and A. Flynn \\ School of Food and Nutritional Sciences, University College Cork, Republic of Ireland
}

The objective of the study was to investigate the contribution of fortified foods to micronutrient intake in Irish adults. Analysis was based on the National Adult Nutrition Survey (NANS), which was carried out between 2008 and 2010 to establish a database of habitual food and drink consumption. A 4-d semi-weighed food record was used to collect food intake data. Analysis of dietary intake data was carried out using WISP ${ }^{\circledR}$ (Tinuviel Software, Anglesey, UK) that is based on McCance and Widdowson's The Composition of Foods, Sixth edition $^{(1)}$. The database was updated to identify all fortified foods recorded ( $6.2 \%$ of the 2552 foods consumed) by participants in the food diary. Fortified foods were identified as having one or more micronutrients listed in the ingredients. The mean daily intake (MDI) of micronutrients in consumers of fortified foods and the \% contribution of fortified foods to the MDI are reported below.

\begin{tabular}{|c|c|c|c|c|c|c|}
\hline \multirow[b]{2}{*}{ Nutrient } & \multicolumn{3}{|c|}{ Males (n 544) } & \multicolumn{3}{|c|}{ Females (n 547) } \\
\hline & Mean Intake/d & SD & $\begin{array}{l}\% \text { Contribution of } \\
\text { fortified foods }\end{array}$ & Mean Intake/d & SD & $\begin{array}{l}\% \text { Contribution of } \\
\text { fortified foods }\end{array}$ \\
\hline Energy kJ (kcal) & $10188.04(2435)$ & $2736.336(654)$ & 8.8 & $7255.056(1734)$ & 2020.8 & 8.3 \\
\hline Retinol $(\mu \mathrm{g})$ & 537 & 720 & 18.5 & 433 & 702 & 17.8 \\
\hline Vitamin $D(\mu \mathrm{g})$ & 4.9 & 7.5 & 20.3 & 4.0 & 5.2 & 20.9 \\
\hline Vitamin E (mg) & 12.3 & 25.1 & 17.3 & 12.5 & 32.2 & 14.9 \\
\hline Vitamin $B_{1}(\mathrm{mg})$ & 2.8 & 4.8 & 18.9 & 3.4 & 10.8 & 17.2 \\
\hline Vitamin $B_{2}(\mathrm{mg})$ & 3.1 & 4.4 & 19.1 & 3.1 & 8.5 & 18.5 \\
\hline Niacin $(\mathrm{mg})$ & 33.8 & 15.2 & 16.3 & 25.3 & 23.8 & 16.4 \\
\hline Vitamin $B_{6}(\mathrm{mg})$ & 4.1 & 4.1 & 21.3 & 4.2 & 10.8 & 21.0 \\
\hline Vitamin $B_{12}(\mu \mathrm{g})$ & 7.2 & 5.4 & 11.6 & 7.7 & 47.4 & 11.1 \\
\hline Folate $(\mu \mathrm{g})$ & 427 & 207 & 28.1 & 355 & 413 & 26.2 \\
\hline $\mathrm{Ca}(\mathrm{mg})$ & 1082 & 411 & 12.6 & 828 & 352 & 11.9 \\
\hline $\mathrm{Fe}(\mathrm{mg})$ & 15.7 & 9.4 & 21.3 & 14.5 & 19.7 & 20.6 \\
\hline
\end{tabular}

Among the 18-64-year-old participants ( $n$ 1274), 86\% reported consumption of a fortified food at least once during the recording period. For consumers of fortified foods, relative to the contribution to mean daily energy intake (9\%), fortified foods contributed significantly to MDI of a range of micronutrients.

The project was funded by the Department of Agriculture, Fisheries and Food under the Food for Health Research Initiative.

1. Food Standards Agency (2002) McCance and Widdowson's The Composition of Foods 6th ed. Cambridge: Royal Society of Chemistry. 